\title{
Carbohydrate-energy restriction may protect the rat brain against oxidative damage and improve physical performance
}

\author{
S. L. de Oliveira ${ }^{1}$, D. B. Diniz ${ }^{2}$ and J. Amaya-Farfan ${ }^{3} *$ \\ ${ }^{1}$ Department of Nutrition, Federal University of Alagoas, Maceió, AL, Brazil \\ ${ }^{2}$ Department of Nutrition, State University of Ceará, Fortaleza, CE, Brazil \\ ${ }^{3}$ Department of Food and Nutrition, State University of Campinas, SP 13.083-970, Brazil
}

(Received 28 September 2001 - Revised 15 August 2002 - Accepted 4 September 2002)

\begin{abstract}
Chronic energy restriction, $\alpha$-tocopherol supplementation and their interaction with exhaustive exercise were investigated. Eleven-week-old male Wistar rats $(n 6 \times 10)$ were fed either a control $(C)$, a $30 \%$ carbohydrate-energy-restricted control $(R)$ or an $\alpha$-tocopherol-supplemented $(S)$ diet for 5 months. The animals in each diet were divided into exercised $(E)$ and non-exercised $(N E)$ groups. Before killing, the exercised rats were required to run to exhaustion (39 (SE 6), 69 (SE 11) and 18 (SE 2) $\min$ for the $C, R$ and $S$ groups, respectively). Lipid peroxidation (thiobarbituric acid-reactive substances; TBARS), protein damage (reactive carbonyls) and $\alpha$ tocopherol were determined in gastrocnemius, liver, brain and/or plasma. There was no difference in lipid peroxidation between the $R$ and $C$ groups, but in liver and muscle peroxidation appeared significantly lower in the $S$ than the other two diets. TBARS in the brain were similar in all groups. On the other hand, reactive carbonyls showed that both the $R$ and $S$ diets reduced protein damage in the brain, while exhaustive exercise increased it. For liver and muscle, however, reactive carbonyl levels were similar in all groups. $\alpha$-Tocopherol supplementation increased the vitamin concentrations in liver, muscle and plasma, but exercise decreased them in plasma and brain. Carbohydrate-energy restriction increased $(P=0.0025)$ resistance to exhaustive exercise considerably without depleting stores of $\alpha$-tocopherol or exacerbating oxidative damage in monitored tissues. It is concluded that while exhaustive exercise promotes a tissue-specific oxidative damage detectable only in brain proteins, both experimental diets tended to ameliorate this condition.
\end{abstract}

Energy restriction: Vitamin E: Oxidative stress: Exercise

Energy restriction, without malnutrition, has been of interest for being the only dietary manipulation capable of increasing life expectancy in several animal species (Masoro, 1985). Although the exact mechanism for such an effect has not been worked out in detail, the evidence gathered so far indicates that energy restriction limits damage to the mitochondria by free radicals ( $\mathrm{Yu}, 1994$; Weindruch, 1996). When the rate of injury exceeds the antioxidant capacity of the system, cell damage may ensue as a result of oxidative stress (Sies, 1994).

Research on energy restriction has produced diverging results. While some workers have found beneficial effects determined by the several indicators of oxidative damage (Koizumi et al. 1987; Rao et al. 1990; Djuric et al. 1992; Youngman et al. 1992; Chen \& Yu, 1994), others report no detectable difference with a normal diet (Masoro et al. 1991; Rojas et al. 1993; Venkatraman et al. 1998). These findings are not necessarily comparable with each other, particularly because of the different types of restriction diet models and the manner in which they have been applied (Rojas et al. 1993).

In this context, another dietary approach intended to diminish oxidative stress is vitamin E supplementation. $\alpha$-Tocopherol, being the main lipid-phase antioxidant, could act in the control of cell membrane oxidative damage (Packer \& Landvik, 1989), while some authors consider that this vitamin counteracts oxidation of proteins and DNA as well (Leibovitz et al. 1990; Garrido et al. 1993; Beales et al. 1994; Haegele et al. 1994; Jain et al. 1996; Ibrahim et al. 1997; Sen et al. 1997; Zhang et al. 1997).

\footnotetext{
Abbreviations: $C$, control; $E$, exercised; MDA, malondialdehyde; $N E$, non-exercised; $R$, energy-restricted control; $S$, supplemented; TBARS, thiobarbituric acid-reactive substances.

* Corresponding author: Professor J. Amaya-Farfan, fax +55 193788 4060, email jaf@fea.unicamp.br
} 
The relationship between intense physical exercise, oxidative stress and increase of free radicals in the body is well known (Novelli et al. 1990; Chow, 1991; Kumar et al. 1992; Alessio, 1993; Goldfarb, 1993). Accumulated damage has been detected in liver, muscle, blood and possibly other tissues (Witt et al. 1992); a single bout of exercise of the appropriate intensity could be sufficient for damage in untrained subjects (Reznick et al. 1992; Viguie et al. 1993; Ji, 1995).

The present work was designed to test the following hypothesis: the combination of a low-carbohydrate diet and a chronic, lower-than-normal food intake can be more advantageous for the adult rat submitted to exhausting physical exercise than vitamin E supplementation.

\section{Materials and methods}

\section{Animals and diets}

Sixty 21-d-old male Wistar rats (Centro de Bioterismo, State University of Campinas, Brazil) were housed in collective cages $\left(22 \pm 2{ }^{\circ} \mathrm{C} ; 12 \mathrm{~h}\right.$ light $-12 \mathrm{~h}$ dark cycles $)$ and fed a commercial laboratory chow (Labina; RalstonPurina do Brasil, Ltd., Campinas, Brazil) ad libitum for an additional 8 weeks, when each was transferred to an individual cage by a randomizing process, to begin the experiment as part of one of three diet groups $(n 3 \times 20)$. The control group $(C)$ had free access to the maintenance AIN-93-M diet (Reeves et al. 1993), while the restricted group $(R)$ received a modified $C$ diet with less carbohydrate and group $S$ was fed diet C ad libitum, but with the addition of 1425 IU of vitamin E (all-rac- $\alpha$-tocopheryl acetate), as detailed in Table 1. Initially, all groups underwent a 1-week adaptation period consuming the control diet.

The restricted diet was formulated in such a way that when offering $70 \%$ of the amount consumed by group $C$, the amounts delivered would be the same for all nutrients as those of group $C$, except for the carbohydrates. Consequently, by restricting diet consumption (or energy intake) to $70 \%$ of that of the controls, the $R$ group was ingesting $40 \%$ less carbohydrate. Diet $S$, in turn, supplied twenty times the amount of vitamin E recommended for the rat (Reeves et al. 1993). In order to keep a closer check over energy consumption, total energy was determined in the diets using a Parr calorimeter (model 1261/ 1563; Moline, IL).

The trial was conducted for 21 weeks and the entire study was performed according to the Guide to the Care and Use of Experimental Animals. The amount of diet to be fed to the $R$ group was determined from the daily average consumed by the $C$ group. Weight changes were monitored and recorded weekly.

\section{Physical test}

Immediately before the end of week twenty-one, the animals of every group were randomly subdivided ( $n 2 \times$ $10)$ into exercised $(E)$ and non-exercised $(N E)$ and fasted overnight. On the day of the exercise test, the animals of the $E$ category were required to run to exhaustion on a six-lane inclined $\left(15^{\circ}\right)$ treadmill (speed $27 \mathrm{~m} / \mathrm{min}$ ). Exhaustion was determined by the animal's refusal to move away from the starting point, where a prod delivered a low-intensity electric stimulus. All of the $N E$ animals were also maintained in the exercising room at the time of the test, in order to randomise the effect of stress. Following exhaustion, serum lactate was determined in a blood sample drawn from the tail vein (ACUSPORT lactimeter; Boehring Mannheim). Immediately after, every exhausted animal was killed by cervical dislodgement along with one of the corresponding $N E$ category.

Gastrocnemius, liver and brain specimens were excised, frozen in liquid $\mathrm{N}_{2}$ and stored at $-80^{\circ} \mathrm{C}$ until analysed. Blood was collected by heart puncture, EDTA was added to the final concentration of $0.034 \mathrm{M}$, then the blood was centrifuged at $1540 \mathrm{~g}$ for $15 \mathrm{~min}$, the plasma recovered and stored in the same manner.

Table 1. Composition of the three diets based on the AIN-93-M diet (Reeves et al. 1993)

\begin{tabular}{lccc}
\hline & \multicolumn{3}{c}{ Diets $(\mathrm{g} / 100 \mathrm{~g})$} \\
\cline { 2 - 4 } Ingredients & Control & Restricted & Supplemented \\
\hline Casein $(85 \mathrm{~g}$ protein/100 g) & 14.00 & 20.00 & 14.00 \\
Maize starch $(87.6 \mathrm{~g} \mathrm{starch} / 100 \mathrm{~g})$ & 62.07 & 54.15 & 62.07 \\
Sucrose $(99.5 \mathrm{~g}$ sucrose/100 g) & 10.00 & 7.22 & 10.00 \\
Soyabean oil & 4.00 & $5 \cdot 71$ & 4.00 \\
Fibre (cellulose) & 5.00 & 5.86 & 5.00 \\
AIN-93-M mineral mixture & 3.50 & 5.00 & 3.50 \\
AIN-93-M vitamin mixture† & 1.00 & 1.43 & 1.00 \\
L-cystine & 0.18 & 0.26 & 0.18 \\
Choline bitartrate & 0.25 & 0.36 & 0.25 \\
Tert-butylhydroquinone & 0.0008 & 0.0011 & 0.0008 \\
All-rac- $\alpha$-tocopheryl acetate $(0.5 \alpha-T E \S)$ & - & - & $0.285 \ddagger$ \\
Total energy $(\mathrm{J})$ & 1454.82 & 1454.44 & 1454.82 \\
\hline
\end{tabular}

* Contains $20.98 \mathrm{~g}$ sucrose $/ 100 \mathrm{~g}$.

† Contains $97.47 \mathrm{~g}$ sucrose $/ 100 \mathrm{~g}$

¥ Sufficient to supply an additional $1425 \mathrm{IU} / \mathrm{kg}$ diet (or a total of $1500 \mathrm{IU} / \mathrm{kg}$ ).

$\S \alpha$-TE: equivalents of $\alpha$-tocopherol; $1 \alpha$-TE $=1 \mathrm{mg} d$ - $\alpha$-tocopherol. 


\section{Lipid peroxidation}

Lipid peroxides were determined by the thiobarbituric acid-reactive substances (TBARS) method as described by Ohkawa et al. (1979), with modifications. The tissue (100 g/l, muscle and liver; $50 \mathrm{~g} / \mathrm{l}$, brain) was homogenised (0.05 M-phosphate buffer, $\mathrm{pH} 7.4 ; 90 \mu \mathrm{M}$-butylhydroxytoluene) in an ice bucket, using a homogenizer with a Teflon pestle. To a sample $(500 \mu \mathrm{l})$ of the homogenate, $1 \mathrm{ml}$ of $0.04 \mathrm{M}-\mathrm{H}_{2} \mathrm{SO}_{4}$ (Merck) and $1 \mathrm{ml}$ of TBA solution (0.046 M-TBA (Sigma Chemical Co.), 0.014 M-sodium dodecylsulfate, $0.06 \mathrm{M}-\mathrm{NaOH}$ (Merck)) were added. To the reagent blanks, $1 \mathrm{ml}$ of the $0.06 \mathrm{M}-\mathrm{NaOH}$ was added in lieu of the TBA solution. The reaction mixture was agitated in a $90^{\circ} \mathrm{C}$ water bath for $20 \mathrm{~min}$. After cooling in an ice bath for $10 \mathrm{~min}, n$-butanol $(3 \mathrm{ml})$ was added with agitation to each reaction tube. This precipitation step was followed by reading the absorbance $(532 \mathrm{~nm})$ of the supernatant fraction obtained after centrifugation at $1978 \mathrm{~g}$ for $15 \mathrm{~min}$. A standard curve was prepared using 1,1,3,3-tetramethoxypropane (Sigma Chemical Co.). Average values obtained from duplicate reactions were expressed as nmole of malondialdehyde (MDA)/mg protein.

\section{Protein oxidation}

The oxidation of protein systems in muscle, liver and brain were quantified as carbonyl compounds reactive to 2,4dinitrophenylhydrazine (Sigma Chemical Co.), as described by Reznick \& Packer (1994). Care was taken to eliminate interference from non-protein, polymeric carbonyls (Levine et al. 1990; Cao \& Cutler, 1995). Before reading the absorbances in the range of $355-390 \mathrm{~nm}$, the u.v. absorbance at $280 \mathrm{~nm}$ was measured in the samples treated with $\mathrm{HCl}$ in order to determine the amount of soluble protein. Results were expressed in terms of nmole of reactive carbonyl compounds/mg protein in the tissue.

\section{$\alpha$-Tocopherol}

Determination of the vitamin was by HPLC, according to Sharma \& Kumar (1990) with modifications. To muscle, liver or brain homogenate, obtained as described for lipid peroxidation, or $200 \mu \mathrm{l}$ plasma (made $9.1 \mathrm{~mm}$ in butylhydroxytoluene), absolute ethanol $(400 \mu \mathrm{l})$ was added and the mixture vortexed for $1 \mathrm{~min}$. After centrifuging $(12000 \mathrm{~g}$ for $5 \mathrm{~min})$, the tocopherol was recovered in methanol following extraction with $n$-hexane. Elution from the HPLC (Varian, model 9012, equipped with a 9075 fluorescent detector) was monitored at 290 (excitation) and $330 \mathrm{~nm}$ (emission). A standard calibration curve of $( \pm)$ - $\alpha$-tocopherol was used for quantification, per unit protein in the tissue.

\section{Statistical analysis}

The data (mean values with their standard errors) were processed by two-way ANOVA and comparisons made by Duncan's ranking test. Differences between means were considered significant when $P \leq 0 \cdot 05$. Computations were carried out using Statistica 5.0 for Windows (StatSoft, Inc.).

\section{Results and discussion}

Weight and point of exhaustion

At the end of the first week of the experimental period the mean weight of the $R$ group already was significantly lower than those of the other two groups $(P=0.003)$; a trend that persisted throughout the entire period. The difference of the final mean weights between the $R$ and the $C$, or the $S$ animals was approximately $100 \mathrm{~g}$ (382 (SE 14), 489 (SE 38 ) and 493 (SE 40), respectively; $P=0.0001$ ).

As seen in Table 2, substantial advantage in physical resistance was shown by the animals of the group receiving the restricted diet, not only with respect to the supplemented, but also to the control group. Exhaustion was reached by the animals of group $R$ in 69 (SE 11) min, whereas those of the $C$ and $S$ groups reached exhaustion at 39 ( $\mathrm{SE} \mathrm{6)}$ and 18 ( $\mathrm{SE} \mathrm{2)} \mathrm{min,} \mathrm{respectively.} \mathrm{Although}$ large, the difference between the means of $C$ and $S$ did not appear significant $(P=0 \cdot 120)$, while that for group $R$ was highly significant $(P=0 \cdot 0025)$. Table 2 also shows that the serum lactate levels were equally elevated in all the diet groups at exhaustion. The possibility of the restricted animals having had a better performance due to the lower body mass load than the supplemented cohorts cannot be discarded in the light of there having been no statistical difference between the latter and the controls. In a separate paper (Oliveira et al. 2002), we have reported that the same restricted diet and feeding protocol resulted in a significantly higher deposition of liver glycogen $(3.8$ times), which in itself could provide an explanation for the augmented physical capacity of these animals.

\section{Lipid peroxidation}

There were significant differences in liver peroxidation as a result of the difference in diets $(P=0.000059)$, although no effect of exercise alone or interactions of this with the diets were detected (Table 2). The TBARS values obtained for the $S$ animals (mean of $0 \cdot 26$ (SE $0 \cdot 01$ ) nmole MDA $/ \mathrm{mg}$ protein, pooling $\mathrm{S} E$ and $\mathrm{S} N E$ ) evidently showed a protective effect of the supplementation $v$. energetic restriction $(0.33$ (SE 0.01)) or $v$. no treatment at all (0.32 (SE 0.01) nmole $\mathrm{MDA} / \mathrm{mg}$ protein). It was interesting to note, furthermore, that there was virtually no difference between the control and the restricted diet, despite the substantially greater work performed by the animals consuming the latter. This means that although the tested type of energy restriction did not show protection against oxidation in absolute terms, a 'latent' protective effect also cannot be ruled out.

Unlike what was observed in liver, both diet and exercise had each an effect $(P=0.016$ and $P=0 \cdot 015$, respectively) on the peroxide levels of muscle, however not in a combined manner (Table 2). Supplementation with $\alpha$-tocopherol resulted in lower pooled mean values of TBARS (0.14 (SE 0.003) nmole MDA/mg protein), against the pooled means for groups $C$ and $R(0.15$ (SE 0.004) and 


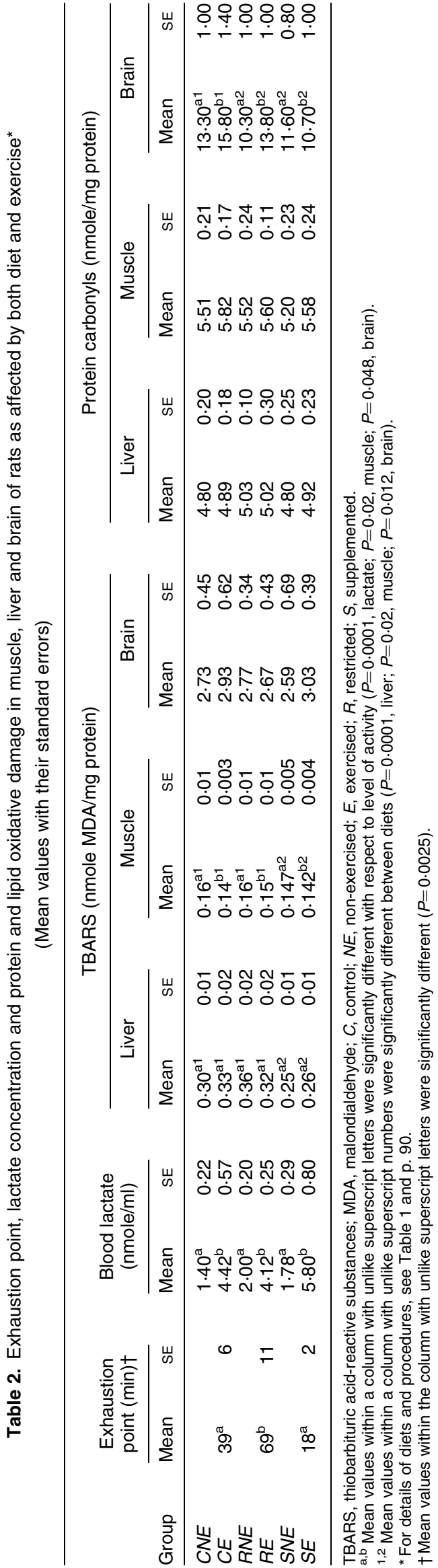

0.16 (SE 0.004) nmole MDA/mg protein, respectively). Similarly, exercise had a significant influence on the level of MDA (0.15 (SE 0.003); 0.16 (SE 0.004) nmole/ mg protein for $E$ and $N E$, respectively). In brain, however, diet and exercise did not result in any differences in TBARS concentration (Table 2).

The literature available in this area has been somewhat controversial. Certain reports, like those of Armeni et al. (1997) and Venkatraman et al. (1998), partly conclude that medium- to long-term general energy restriction does not offer protection against lipid peroxidation, although Rao et al. (1990) reported reduction of the TBARS values in the livers of rodents fed energy-restricted diets for 11 and 20 months, while Koizumi et al. (1987) already claimed that there was a reduction in the levels of hepatic lipid peroxidation of mice after an 11-month feeding trial with carbohydrate-specific energy restriction, but not for the period of 23 months.

Rojas et al. (1993), in turn, reported not a reduction, but an increase of the levels of TBARS, as well of the sensitivity to lipid peroxidation attributed to carbohydrateenergy restriction in mice. However, when the effect of general food restriction was also studied by the same authors, such an effect was not observed. Since the restriction models were of short duration, the authors concluded that short-term restriction had no antioxidant effect. These workers were also led to conclude that energetic restriction resulted in some kind of metabolic imbalance responsible for the higher lipid peroxidation. In this respect, it is important to emphasise that the strategy used by such authors to cut carbohydrates could have been in itself the source of the metabolic imbalance. Replacing fibre for metabolisable carbohydrates raised the fibre content to levels close to $450 \mathrm{~g} / \mathrm{kg}$ diet could conceivably interfere with the absorption of minerals and other nutrients.

Supplementation with $\alpha$-tocopherol clearly lowered the values of TBARS in both liver and muscle, independent of physical activity. Such an effect was evident in relation to either the standard control AIN-93 or the restricted diet. The protective effect of $\alpha$-tocopherol supplementation we report here, nevertheless, is similar to that described in other studies. For instance, decreasing TBARS values have been reported in rat liver and heart (Leibovitz et al. 1990), erythrocytes (Zamora et al. 1991; Garrido et al. 1993), plasma and muscle (Goldfarb et al. 1994; Sen et al. 1997), and even liver in the animals receiving different types of fat (Ibrahim et al. 1997; Sen et al. 1997).

On the other hand, the protecting action observed in liver and muscle was not seen in brain, which suggests the effect being tissue-specific. Higher concentrations of TBARS were encountered in this tissue than in any of the others studied. It is known that brain is particularly susceptible to damage promoted by free radical species. Besides its high rates of $\mathrm{O}_{2}$ consumption and elevated concentration of polyunsaturated fatty acids involved in membrane structure, such tissue is relatively poor in antioxidant enzymes and other oxidant-protecting substances (Carney \& Carney, 1994; Mo et al. 1996; Joseph et al. 1998). It is possible, however, that the doses of $\alpha$-tocopherol used were still insufficient for the effect to be detected. 
On analysing the effect of intense physical activity on peroxidation, our data showed that while TBARS levels were not altered in either liver or brain, the levels in muscle were slightly diminished $(P=0.02$, Table 2$)$. It is pertinent to emphasise that both the intensity of the exercise and the stage of recovery are factors to be considered when analysing oxidative stress (Witt et al. 1992; Alessio, 1993; Ji, 1995). Ji et al. (1992) were able to detect an increase in peroxidation only for levels 3 and 5, of five different levels of intensity on a treadmill. Our results were consistent with those of Venkatraman et al. (1998), who did not observe an increase of liver lipid peroxidation in rats, even after 2 months of daily sessions of exhaustive exercise. With respect to the influence of the post-exhaustion (recovery) time on the oxidation levels, we should mention that in an experiment in which rats were brought to exhaustion without previous training ( $\mathrm{Li}$ et al. 1999), it was shown that the levels of TBARS were already higher at the end of exhaustion, although full recovery was seen only after $48 \mathrm{~h}$ of recovery. In the present study, the substantially greater amount of work performed by the restricted group allows us to conclude that the carbohydrate-specific energy restriction employed was conducive to higher physical resistance, while not showing alteration in lipid peroxidation in the tissues assayed.

\section{Protein oxidative damage}

The data on protein carbonyl accumulation in both liver and muscle revealed no significant differences, due to either the diets or exercise $(P>0 \cdot 05)$, as seen in Table 2 . Such a result suggests that these two organs have little sensitivity to factors that promote the increase of reactive carbonyls on proteins. In brain, once again, the response was different from that seen in the other tissues. Regarding the effect of the diet, both the carbohydrate-energy restriction and supplementation with $\alpha$-tocopherol displayed protection against protein oxidative damage in the brain $(P=0.012)$, whereas acute physical activity, as expected, was alone responsible for increased levels of protein oxidative stress $(P=0 \cdot 048)$. Consistent with the observation that levels of lipid peroxidation appear higher in brain than in liver or muscle, the data from reactive carbonyls reinforce the notion that brain tissue is particularly sensitive to oxidative stress.

Inasmuch as the consequences of the diet or exhaustive exercise on oxidative damage, measurable by the level of protein-bound reactive carbonyl products in either liver or muscle, no differences were detected. In brain, however, the protective effect of the two antioxidant diets and the oxidative damage promoted by exhaustive exercise were evident. Other workers reported that such carbonyls are diminished in rat liver (Youngman et al. 1992) and mouse brain (Dubey et al. 1996) as a result of energetic restriction, while vitamin $\mathrm{E}$ supplementation has shown a similar response (Reznick et al. 1992; Ibrahim et al. 1997; Sen et al. 1997). Although this biochemical indicator has been less explored than lipid oxidation, the data are no less subject to controversy, first because of different experimental conditions and then because of the occasional interference of analytical artefacts (Cao \& Cutler, 1995).
Despite its shortcomings, earlier claims made as to the effect of vitamin E supplementation on exhaustive exercise (Reznick et al. 1992; Sen et al. 1997) have not been confirmed. An effort was made in the present study to minimize the interference of nucleic acids, although the total elimination of unreacted 2,4-dinitrophenylhydrazine from the reaction mixture was not accomplished.

The issue of why physical exercise may lead to oxidative stress of the protein type in the brain is not yet understood. The work of Radák et al. (2001) reported that a basal level of reducing (anti-oxidative) activity exists in brain and that regular exercise can promote an increase in this metabolic activity, improving the cognitive function and decreasing oxidative damage, as detected by the protein carbonyls, but not by TBARS or DNA alterations. It thus seems possible that both exercise and diet, alone or in combination, can have an effect on the oxidative level of brain proteins.

\section{$\alpha$-Tocopherol}

$\alpha$-Tocopherol concentration varied according to the tissue and the diet group. Liver and muscle tissues of the supplemented animals exhibited the highest stocks of $\alpha$-tocopherol (3.25 (SE 0.22) and 0.25 (SE 0.006) $\mu \mathrm{g} / \mathrm{mg}$ protein, respectively), as expected from their massive intake. The remaining $C$ and $R$ groups showed corresponding liver concentrations of 0.25 (SE 0.006) and 0.31 (SE 0.012) $\mu \mathrm{g} / \mathrm{mg}$ protein, and 0.14 (SE 0.005) and 0.13 (SE 0.006) $\mu \mathrm{g} / \mathrm{mg}$ of muscle protein, respectively. In this case again, exercise did not seem to modify the $\alpha$-tocopherol concentrations, nor did it show interaction with the diets (Table 3 ).

In plasma, however, both diet $(P=0.0001)$ and exercise $(P=0.006)$ had each an isolated effect on the tocopherol levels. For the supplemented animals, the mean level was 6.4 (SE 0.5) $\mu \mathrm{g} / \mathrm{mg}$ protein, compared with 2.9 (SE 0.2) and $3 \cdot 3($ SE $0 \cdot 2) \mu \mathrm{g} / \mathrm{mg}$ protein, for groups $C$ and $R$, respectively. Exhaustive exercise, however, had the net result of lowering the overall mean concentrations from 4.9 (SE 0.6) to 3.6 (SE 0.3) $\mu \mathrm{g} / \mathrm{mg}$ protein.

Finally, in brain, rather than in the other tissues, an interaction between diet and exercise was apparent, indicating that extra accretions in $\alpha$-tocopherol gained through supplementation were used up during the exhaustive exercise, thus making final levels similar to those of the animals fed normal doses of $\alpha$-tocopherol $(P=0 \cdot 0016)$. Neither carbohydrate-energy restriction nor exhaustive exercise in this diet group brought about any significant differences on the final antioxidant vitamin levels.

At first glance, the data readily showed that a 20-fold higher $\alpha$-tocopherol intake did not result in increments in the concentration of comparable magnitude in the tissues analysed, but rather increases that were commensurate with the tissue's mass and its specialised functions. In terms of concentration, for instance, it could be seen that increases were more prominent in liver tissue than were for muscle, brain or plasma, which in turn was consistent with the specific storage and regulatory functions of the liver.

The role of vitamin $\mathrm{E}$ in counteracting oxidative stress in cell membranes has been extensively studied and is reasonably well established. With the expectation of 
Table 3. Effect of diet and exercise on the concentration of $\alpha$-tocopherol in liver, muscle, brain and plasma*

(Mean values with their standard errors)

\begin{tabular}{|c|c|c|c|c|c|c|c|c|}
\hline \multirow[b]{3}{*}{ Group } & \multicolumn{8}{|c|}{$\alpha$-Tocopherol ( $\mu \mathrm{g} / \mathrm{mg}$ protein) } \\
\hline & \multicolumn{2}{|c|}{ Liver } & \multicolumn{2}{|c|}{ Muscle } & \multicolumn{2}{|c|}{ Plasma } & \multicolumn{2}{|c|}{ Braint } \\
\hline & Mean & SE & Mean & SE & Mean & SE & Mean & SE \\
\hline CNE & $0.62^{\mathrm{a} 1}$ & 0.02 & $0.34^{\mathrm{a} 1}$ & 0.01 & $17 \cdot 5^{\mathrm{a} 1}$ & 1.6 & $0.32^{\mathrm{a}}$ & 0.02 \\
\hline$C E$ & $0.62^{a 1}$ & 0.02 & $0.38^{\mathrm{a} 1}$ & 0.02 & $12 \cdot 4^{\mathrm{b} 1}$ & $1 \cdot 2$ & $0.32^{\mathrm{a}}$ & 0.05 \\
\hline $\mathrm{R} N E$ & $0.74^{\mathrm{a} 1}$ & 0.04 & $0.34^{\mathrm{a} 1}$ & 0.02 & $17 \cdot 2^{\mathrm{a} 1}$ & 1.8 & $0.28^{\mathrm{a}}$ & 0.03 \\
\hline $\mathrm{RE}$ & $0.84^{\mathrm{a} 1}$ & 0.04 & $0.32^{\mathrm{a} 1}$ & 0.02 & $15 \cdot 3^{b 1}$ & $1 \cdot 1$ & $0.27^{\mathrm{a}}$ & 0.03 \\
\hline SNE & $8 \cdot 27^{\mathrm{a} 2}$ & 0.85 & $0.60^{\mathrm{a} 2}$ & 0.02 & $36 \cdot 6^{\mathrm{a} 2}$ & 3.7 & $0.47^{b}$ & 0.05 \\
\hline$S E$ & $7.97^{\mathrm{a} 2}$ & 0.68 & $0.65^{\mathrm{a} 2}$ & 0.03 & $26 \cdot 3^{\mathrm{b} 2}$ & 1.8 & $0.30^{\mathrm{a}}$ & 0.03 \\
\hline
\end{tabular}

$C$, control; $N E$, non-exercised; $E$, exercised; $R$, restricted; $S$, supplemented.

a,b Mean values within a column with unlike superscript letters were significantly different with respect to level of activity $(P=0.04)$.

${ }^{1,2}$ Mean values within a column with unlike superscript numbers were significantly different between diets $(P=0.0001)$.

${ }^{*}$ For details of diets and procedures, see Table 1 and p. 90.

tMean values within the column with unlike superscript letters were significantly different $(P=0.0016)$.

maximising its beneficial effects, numerous scientists have employed a variety of dosages under various experimental conditions. The amounts used in the present study, representing something close to half the dosage suggested by some orthomolecular therapists in cases of stress, produced expectedly higher stocks of the vitamin in the analysed tissues, except brain, in both the rested and exercised states. The higher $\alpha$-tocopherol levels in the tissues such as liver and muscle, but not brain, were accompanied by lower TBARS values.

Energy restriction alone has been shown to have an effect on another antioxidant parameter. Using both a food-restriction scheme that permitted the combined carbohydrate-energy and general restriction, Rojas et al. (1993) found decreased levels of ascorbic acid in several tissues. It should be pointed out, however, that in the present study no alteration was observed in tissue levels of the antioxidant parameter we chose, vitamin E. This and other results produced by the restricted diet could have originated from two different effects. It should be kept in mind that in order to accomplish the desired energy-restriction model, alteration of the carbohydrate content of the diet was chosen as one that could carry an influence on nutrient balance that could be least critical. This manipulation, however, may have lead to an additional effect besides that resulting from the simple total energy restriction. The present experimental model, however, did not offer the possibility of separating these two effects.

With respect to the influence of exercise on the $\alpha$-tocopherol parameter, changes were observed only in terms of lower concentrations of the vitamin in plasma and brain. In this context, however, the consulted literature refers to a diversity of results, including one describing no effect on the concentration of this vitamin in muscle after exhaustive exercise on the moving platform (Warren et al. 1992), just as observed in the present study. On the other hand, some have reported reduction in muscle (Reznick et al. 1992; Sen et al. 1997) and in liver (Sen et al. 1997), as well as elevation in liver and muscle and decrease in plasma in animals that had received previous training (Benderitter et al. 1996). It should be remembered, furthermore, that vitamin $\mathrm{E}$ stores may undergo redistribution among the different tissues and fasting and exercise are factors that can affect mobilisation (Parker, 1989). Data from the present and other studies support the idea that the observed lower plasma levels could be the result of rapid mobilisation from blood into muscle, and perhaps other tissues, accompanied by a slower replenishment from hepatic stores.

\section{Conclusions}

From the data presented, it can be concluded that the exercise imposed did not result in oxidative stress observable in liver or muscle tissues, although oxidative damage was detected in the brain proteins of the rats. $\alpha$-Tocopherol supplementation, at a level of 20 times the recommended dosage, but not $30 \%$ carbohydrate-specific energy restriction, offered protection in terms of lipid peroxidation in the liver and the muscle, while not in brain. On the other hand, as evidenced by the protein oxidation levels in brain, both the restricted and the supplemented diets did offer a certain antioxidant protection, thus suggesting that there was a tissue-specific effect afforded by the different diets. Considering that this energy-restriction model resulted in a substantial increase of the animal's resistance to exhaustion, and the finding that levels of TBARS and protein carbonyls in both liver and muscle were indistinguishable from those of the control animals, it can be concluded that such a restriction model may offer a true advantage over $\alpha$-tocopherol supplementation.

\section{Acknowledgements}

The authors thank Dr Denise V de Macedo and her staff for her valuable contribution to the exercise set-up. Thanks are 
also due to PICD of CAPES, Brazil, for the doctoral fellowships to DB Diniz and SL de Oliveira.

\section{References}

Alessio HM (1993) Exercise-induced oxidative stress. Medicine and Science in Sports Exercise 25, 218-224.

Armeni T, Tomasetti M, Baroni SS, Saccucci F, Marra M, Pieri C, Littarru GP, Principato G \& Battino M (1997) Dietary restriction affects antioxidants levels in rat liver mitochondria during ageing. Molecular Aspects of Medicine 18, S247-S250.

Beales PE, Williams AJK, Albertini MC \& Pozzilli E (1994) Vitamin $\mathrm{E}$ delays diabetes onset in the non-obese diabetic mouse. Hormonal Metabolism Research 26, 450-452.

Benderitter M, Hadj-Saad F, Lhuissier M, Maupoil V, Guilland J-C \& Rochette L (1996) Effects of exhaustive exercise and vitamin $\mathrm{B}_{6}$ deficiency on free radical oxidative process in male trained rats. Free Radical Biology and Medicine 21 , 541-549.

Cao G \& Cutler R (1995) Protein Oxidation and Aging. I. Difficulties in measuring reactive protein carbonyls in tissues using 2,4-dinitrophenylhydrazine. Archives of Biochemistry and Biophysics 320, 106-114.

Carney JM \& Carney AM (1994) Role of protein oxidation in aging and in age-associated neurodegenerative diseases. Life Sciences 25/26, 2097-2103.

Chen JJ \& Yu BP (1994) Alterations in mitochondrial membrane fluidity by lipid peroxidation products. Free Radical Biology and Medicine 17, 411-418.

Chow CK (1991) Vitamin E and oxidative stress. Free Radical Biology and Medicine 11, 215-232.

Djuric Z, Lu MH, Lewis SM, Luongo DA, Chen XW, Heilbrun LK, Reading BA, Duffy PH \& Hart RW (1992) Oxidative DNA damage levels in rats fed low fat, high fat, or calorierestricted diets. Toxicology and Applied Pharmacology 115 , $156-160$.

Dubey A, Forster MJ, Lal H \& Sohal RS (1996) Effect of age on caloric intake on protein oxidation on different brain regions and on behavioral functions of the mouse. Archives of Biochemistry and Biophysics 333, 189-197.

Garrido A, Gárate M, Campos R, Villa A, Nieto S \& Valenzuela A (1993) Increased susceptibility of cellular membranes to the induction of oxidative stress after ingestion of high doses of fish oil: effect of aging and protective action of dl- $\alpha$-tocoferol supplementation. Journal of Nutritional Biochemistry $\mathbf{4}$, $118-122$.

Goldfarb AH (1993) Antioxidants: role of supplementation to prevent exercise-induced oxidative stress. Medicine and Science in Sports and Exercise 25, 232-236.

Goldfarb AH, Mcintosh MK, Boyer BT \& Fatouros J (1994) Vitamin E effects on indexes of lipid peroxidation in muscle from DHEA-treated and exercised rats. Journal of Applied Physiology 76, 1630-1635.

Haegele AD, Briggs SP \& Thompson HJ (1994) Antioxidant status and dietary lipid unsaturation modulate oxidative DNA damage. Free Radical Biology and Medicine 16, 111-115.

Ibrahim W, Lee U-S, Yeh C-C, Szabo J, Bruckner G \& Chow CK (1997) Oxidative stress and antioxidants status in mouse liver: effects of dietary lipid, vitamin E and iron. Journal of Nutrition 127, 1401-1406.

Jain SK, McVie R, Jaramillo JJ, Palmer M, Smith T, Meachum ZD \& Little RL (1996) The effect of modest vitamin E supplementation on lipid peroxidation products and other cardiovascular risk factors in diabetic patients. Lipids 31, S87-S90.

Ji LL (1995) Oxidative stress during exercise: implication of antioxidant nutrients. Free Radical Biology and Medicine $\mathbf{1 8}$ 1079-1086

Ji LL, Fu R \& Mitchell EW (1992) Glutathione and antioxidant enzymes in skeletal muscle: effects of fiber type and exercise intensity. Journal of Applied Physiology 73, 1854-1859.

Joseph JA, Shukitt-Hale B, Denisov NA, Prior RL, Cao G, Martin A, Taglialatela G \& Bickford PC (1998) Long-term dietary strawberry, spinach, or vitamin E supplementation retards the onset of age-related neuronal signal-transduction and cognitive behavioral deficits. Journal of Neuroscience 19, 8047-8055.

Koizumi A, Weindruch R \& Walford RL (1987) Influences of dietary restriction and age on liver enzyme activities and lipid peroxidation in mice. Journal of Nutrition 117, 361-367.

Kumar CT, Reddy VK, Prasad M, Thyagaraju K \& Reddanna P (1992) Dietary supplementation of vitamin $\mathrm{E}$ protects heart tissue from exercise-induced oxidant stress. Molecular and Cellular Biochemistry 111, 109-115.

Leibovitz BE, Hu M-L \& Tappel AL (1990) Lipid peroxidation in rat tissue slices: effect of dietary vitamin E, corn oil-lard and menhaden oil. Lipids 25, 125-129.

Levine RL, Garland D, Oliver CN, Amici A, Climent I, Lenz AG, Ahn B-W, Shaltiel S \& Stadtman ER (1990) Determination of carbonyl content in oxidatively modified proteins. Methods in Enzymology 186, 465-478.

Li JX, Tong CWC, Xu DQ \& Chan KM (1999) Changes in membrane fluidity and lipid peroxidation of skeletal muscle mitochondria after exhausting exercise in rats. European Journal of Applied Physiology 80, 113-117.

Masoro EJ (1985) Nutrition and Aging - A current assessment. Journal of Nutrition 115, 842-848.

Masoro EJ, Shimokawa I \& Yu BP (1991) Retardation of the aging processes in rats by food restriction. Annals of the New York Academy of Sciences 621, 337-352.

Mo JK, Hom DG \& Andersen JK (1996) Decreases in protective enzymes correlates with increased oxidative damage in the aging mouse brain. Mechanisms of Ageing and Development 2/3, 73-82.

Novelli GP, Bracciotti G \& Falsini S (1990) Spin-trappers and vitamin $\mathrm{E}$ prolong endurance to muscle fatigue in mice. Free Radical Biology and Medicine 8, 9-13.

Ohkawa H, Ohishi N \& Yagi K (1979) Assay for lipid peroxides in animal tissues by thiobarbituric acid reaction. Analytical Biochemistry 95, 351-358.

Olfert ED, Cron BM \& McWilliam AA (eds) (1993) Guide to the Care and Use of Experimental Animals, 2nd edn. Canadian Council on Animal Care, 1(2).

Oliveira SL, Diniz DB \& Amaya-Farfan J (2002) Alterações metabólicas induzidas pela restrição energética e pela suplementação com vitamina $\mathrm{E}$ em ratos submetidos ao exercício (Altered metabolism induced by restriction of energy and by supplementation with vitamin $\mathrm{E}$ in rats submitted to exercise). Revista de Nutrição 15(3), 283-290.

Packer L \& Landvik S (1989) Vitamin E: introduction to biochemistry and health benefits. Annals of the New York Academy of Sciences 570, 1-6.

Parker RS (1989) Dietary and Biochemical Aspects of Vitamin E. Advances in Food and Nutrition Research 33, 157-232.

Radák Z, Kaneko T, Tahara S, Nakamoto H, Pucsok J, Sasvári M, Nyakas C \& Goto S (2001) Regular exercise improves cognitive function and decreases oxidative damage in rat brain. Neurochemistry International 38, 17-23.

Rao G, Xia E, Nadakavukaren MJ \& Richardson A (1990) Effect of dietary restriction on the age-dependent changes in the expression of antioxidant enzymes in rat liver. Journal of Nutrition 120, 602-609.

Reeves PG, Nielsen FH \& Fahey GC Jr (1993) AIN-93 purified diets for laboratory rodents: final report of the American Institute of 
Nutrition Ad Hoc Writing Committee on the reformulation of the AIN-76 rodent diet. Journal of Nutrition 123, 1939-1951.

Reznick AZ \& Packer L (1994) Oxidative damage to proteins spectrophotometric method for carbonyl assay. Methods in Enzymology 233, 357-363.

Reznick AZ, Witt E, Matsumoto M \& Packer L (1992) Vitamin $\mathrm{E}$ inhibits protein oxidation in skeletal muscle of resting and exercised rats. Biochemical and Biophysical Research Communications 189, 801-806.

Rojas C, Cadenas S, Pérez-Campo R, Lopez-Torres M, Pamplona R, Prat J \& Barza G (1993) Relationship between lipid peroxidation, fatty acid composition, and ascorbic acid in the liver during carbohydrate and caloric restriction in mice. Archives of Biochemistry and Biophysics 306, 59-64.

Sen CK, Atalay M, Agren J, Laaksonen DE, Roy S \& Hanninen O (1997) Fish oil and vitamin E supplementation in oxidative stress at rest and after physical exercise. Journal of Applied Physiology 83, 189-195.

Sharma A \& Kumar A (1990) Concurrent analysis of plasma retinol and $\alpha$-tocoferol by isocratic HPLC. Indian Journal of Experimental Biology 28, 780-782.

Sies H (1994) Oxidative stress: from basic research to clinical medicine. In Trace Elements and Free Radicals in Oxidative Stress, pp. 1-6 [AE Favier, J Néve and P Faure, editors]. Champaign, IL: AOCS PRESS.

Venkatraman JT, Angkeow P \& Fernandes G (1998) Effects of food restriction on antioxidant defence system in exercised rats. Nutrition Research 18, 283-298.
Viguie CA, Frei B, Shigenaga MK, Ames BN, Packer L \& Brooks GA (1993) Antioxidant status and indexes of oxidative stress during consecutive days of exercise. Journal of Applied Physiology 75, 566-572.

Warren JA, Jenkins RR, Packer L, Witt EH \& Armstrong RB (1992) Elevated muscle vitamin E does not attenuate eccentric exercise-induced muscle injury. Journal of Applied Physiology 72, 2168-2175.

Weindruch R (1996) Caloric restriction and aging. Scientific American 274, 32-38.

Witt EH, Reznick AZ, Viguie CA, Starke-Reed P \& Packer L (1992) Exercise, oxidative damage and effects of antioxidant manipulation. Journal of Nutrition 122, 766-773.

Youngman LD, Park J-Y \& Ames BN (1992) Protein oxidation associated with aging is reduced by dietary restriction of protein or calories. Proceedings of the National Academy of Sciences USA 89, 9112-9116.

Yu BP (1994) How diet influences the aging process of the rat. Proceedings of the Society for Experimental Biology and Medicine 205, 97-105.

Zamora R, Hidalgo FJ \& Tappel AL (1991) Comparative antioxidant effectiveness of dietary $\beta$-carotene, vitamin $\mathrm{E}$, selenium and coenzyme $\mathrm{Q}_{10}$ in rat erythrocytes and plasma. Journal of Nutrition 121, 50-56.

Zhang D, Okada S, Yu Y, Zheng P, Yamaguchi R \& Kasai H (1997) Vitamin E inhibits apoptosis, DNA modification and cancer incidence induced by iron-mediated peroxidation in Wistar rat kidney. Cancer Research 57, 2410-2414. 